\title{
Radiative Properties of High Wire Number
}

Tungsten Arrays with Implosion Times up to 250 ns

C. Deeney,,$\dot{\uparrow}$ C.A. Coverdale, M.R. Douglas, K.W. Struve, R.B. Spielman, W.A. Stygar, D.L. Peterson, ${ }^{\mathrm{a}}$ and N.F. Roderick ${ }^{\mathrm{b}}$

Sandia National Laboratories, P.O. Box 5800

Albuquerque, NM 87185.

M.G. Haines, F.N. Beg, and J. Ruiz-Camacho

Plasma Physics Group, Imperial College

London, SW7 2BZ

High wire number, $25-\mathrm{mm}$ diameter tungsten wire arrays have been imploded on the 8-MA Saturn generator, operating in a long-pulse mode. By varying the mass load from 710 to 6140 $\mu \mathrm{g} / \mathrm{cm}$, implosion times of 130 to $250 \mathrm{~ns}$ have been obtained with implosion velocities of 50 to $25 \mathrm{~cm} / \mu$ s, respectively. These z-pinch implosions produced plasmas with millimeter diameters that radiated 600 to $800 \mathrm{~kJ}$ of $\mathrm{x}$-rays, with powers of 20 to 49 TW; the corresponding pulsewidths were 19 to $7.5 \mathrm{~ns}$, with risetimes ranging from 6.5 to 4.0 ns. These powers and pulsewidths are similar to those achieved with 50 ns implosion times on Saturn. Two-dimensional, radiationmagnetohydrodynamic calculations indicate that the imploding shells in these long implosion time experiments are comparable in width to those in the short pulse cases. This can only be due to lower initial perturbations. A heuristic wire array model suggests that the reduced perturbations, in the long pulse cases, may be due to the individual wire merger occurring well before the acceleration of the shell. The experiments and modeling suggest that 150 to $200 \mathrm{~ns}$ implosion time $\mathrm{z}$-pinches could be employed for high-power, $\mathrm{x}$-ray source applications.

a) Permanent address: Los Alamos National Laboratory, MS-B259, Los Alamos, NM 87545.

b) Permanent address: University of New Mexico, Albuquerque, NM 87131.

$\dagger$ cdeene@sandia.gov

PACS 52.25.Nr, 52.65.-y, 52.55.Ez, 52.50.L 


\section{DISCLAIMER}

This report was prepared as an account of work sponsored by an agency of the United States Government. Neither the United States Government nor any agency thereof, nor any of their employees, make any warranty, express or implied, or assumes any legal liability or responsibility for the accuracy, completeness, or usefulness of any information, apparatus, product, or process disclosed, or represents that its use would not infringe privately owned rights. Reference herein to any specific commercial product, process, or service by trade name, trademark, manufacturer, or otherwise does not necessarily constitute or imply its endorsement, recommendation, or favoring by the United States Government or any agency thereof. The views and opinions of authors expressed herein do not necessarily state or reflect those of the United States Government or any agency thereof. 


\section{DISCLAIMER}

Portions of this document may be illegible in electronic image products. Images are produced from the best available original document. 


\section{Introduction.}

Historically, long implosion time $\left(0.1 \mu \mathrm{s}<\tau_{\text {imp }}<2.0 \mu \mathrm{s}\right)$ z-pinch regimes have been studied because of their potential to reduce the operating voltage that high-current, pulsed-power machines require. A lower operating voltage usually results in simpler power flow and reductions in the cost of the generator. Experiments on SHIVA [1], PEGASUS [2], FALCON [3], and HAWK [4] have pursued this arena of z-pinch research, particularly for applications where the $\mathrm{x}$-ray yield is important but high powers are not needed. Based on the results of these previous long implosion time experiments, high power applications, such as vacuum hohlraums and "flying radiation case" experiments $[5,6]$, were assumed to require 100 ns class pulsedpower drivers to obtain the requisite short, high-power $\mathrm{x}$-ray pulses. Recent advances in z-pinch wire array designs have resulted in substantial increases in $\mathrm{X}$-ray power from pulsed power generators [7-11] and have opened avenues for pursuing high-power, long implosiōn time systems.

Simple stability scaling arguments have always assumed that the output $x$-ray pulsewidth would be some fraction of the implosion time, hence the belief that the $x$-ray power would decrease as the implosion time increased for a given kinetic energy. If the $x$-ray pulsewidth is a multiple of the thermalization time of the radial kinetic energy, then the hypothesis regarding pulsewidth versus implosion time is evident. The thermalization time is given by $\Delta \mathrm{r} / \mathrm{V}_{\mathrm{f}}$ where $\Delta \mathrm{r}$ is a characteristic sheath thickness at stagnation and $V_{\mathrm{f}}$ is the maximum implosion velocity.[12] The maximum velocity scales inversely with the implosion time. Since the aspect ratio, i.e. initial diameter to dominant Rayleigh-Taylor (RT) instability wavelength, is constant, then $\Delta \mathrm{r}$ should be independent of implosion time. Consequently, the pulsewidth should scale linearly with the implosion time. If another approach is taken where the initial diameter is increased to keep $V_{f}$ constant, then as the implosion time increases, the aspect ratio increases, which could lead to an even 
faster than linear increase in $\Delta \mathrm{r}$ due to $\mathrm{RT}$ broadening. The pulsewidth, again, should increase with implosion time.

The pessimism that follows from these simple arguments has been brought into question by advances in z-pinch research. In the past few years, work has shown that the choice of load design can reduce asymmetries, and the possible initial seeding of implosion instabilities.[7-11] Moreover, these designs are complemented by techniques that have been demonstrated to mitigate the growth of RT instabilities.[13-16] As a result, wire arrays imploded in 100 ns or less can produce 4 to 8 ns pulsewidths, consequently it may be possible to increase the implosion time without the increase in pulsewidth being too detrimental for many high power applications. In addition, the thermalization of the implosion kinetic energy is not the only energy input [17], and RT growth is not the only significant factor in wire array dynamics.[18-20] Such effects may also cause the pulsewidth scaling with implosion time to be different than as discussed above. Based on all this increased understanding of energy flow and improved z-pinch dynamics, it is therefore possible to envision load designs that would enable high output power, 150 to 250-ns z-pinch implosions for hohlraum applications. In fact, high wire number array designs have already allowed the high power performance of 50-ns implosions on Saturn [7] to be scaled effectively to the $100 \mathrm{~ns}$ implosion times of the $\mathrm{Z}$ accelerator.[9]

In this paper, a series of tungsten wire array experiments are presented, which were performed on the Saturn generator [21] to study the effect of increasing implosion time (up to $250 \mathrm{~ns}$ ) on total $x$-ray radiated energy and power. A mass scan with $25 \mathrm{~mm}$ diameter arrays was chosen in order to have an overlap with the velocities achieved in the short pulse mode, and to look at the implosion time scaling at diameters relevant for vacuum hohlraums.

The long pulse experiments were possible due to a simple modification to the waterline pulse power system of Saturn, described in Section II, which permits the generator to operate either 
as a 8-MA, 50-ns, 20-TW, or as a 8-MA, 230-ns, 5-TW pulsed power generator. The availability of tungsten wire load data from Saturn in the short pulse mode [7] made the Saturn facility ideal for these experiments. The wire array load hardware used in these experiments is listed in Table 1 and described in section II. The circuit modeling and the z-pinch diagnostics are also described in detail in Section II. Section III describes the experimental results, where the metrics of implosion quality include $x$-ray power, risetime, pulsewidth, and z-pinch diameter. The experimental results are compared to previous short pulse tungsten experiments performed on Saturn in Section IV. In Section V, conclusions are made and future experiments and calculations are proposed.

\section{The Saturn generator, wire array hardware, and z- pinch diagnostics.}

The 8 MA Saturn generator [21] is shown in Figure 1(a). Saturn stores $5 \mathrm{MJ}$ of electrical energy in the Marx banks which, when fired, erect to almost $3 \mathrm{MV}$ and pulse charge the water-dielectric intermediate energy stores (IES). Thirty-six high pressure gas switches are electrically triggered to discharge the intermediate stores, and to pulse charge the water pulse forming lines, referred to as "line-ones." In normal short pulse operation, the water output switches on the 36 line-ones are set to a nominal $7 \mathrm{~cm}$ gap. The lineones discharge when these output switches break down to produce a $8 \mathrm{MA}, 20 \mathrm{TW}, 50 \mathrm{~ns}$ electrical power pulse at the water-vacuum interface. Typical voltage waveforms at the Marx, IES, line-one and the insulator stack are depicted in Figure 1(b). A simple modification to the waterline, i.e., shorting the output switches, allows the lineones to act as compensation capacitors to the inductance of the gas switches instead of as pulse-forming lines. The resulting voltage waveforms, in particular the line-one and stack voltages, are shown in Figure 1(c). This new long pulse mode, which generates a 5 TW, 230 ns electrical pulse at the water-vacuum interface, produces 11.5 MA with a short circuit load (see Figure 2). 
An example of the wire array hardware employed in these experiments is shown in Figure 3. Concerns about plasma closure of the magnetically insulated transmission lines (MITLs) near the load prompted the use of cleaning and coating procedures that are routine on the 20-MA $\mathrm{Z}$ accelerator. The anode and cathode structures were chemically cleaned, vacuum baked, hydrogen fired, and finally gold coated. Calibrated, NiChrome-shielded B-dots, located downstream of the convolute posts, were used to measure the load current. The wire arrays consisted of 180 or $300,2 \mathrm{~cm}$ long tungsten wires, with individual wire diameters ranging from 5.1 to $15 \mu \mathrm{m}$, as listed in Table 1. For the initial diameter of $25 \mathrm{~mm}$, calculated implosion velocities of 50 to $25 \mathrm{~cm} / \mu \mathrm{s}$ were possible with the 130 to $250 \mathrm{~ns}$ implosion times. For comparison, in the short pulse mode, the 50 $\mathrm{cm} /$ us velocity was achieved using a $12.5 \mathrm{~mm}$ initial diameter array.

A circuit model was developed which included the four MITLs, the convolute, a zero-dimensional slug model, and the electrical circuit back to the water IES. This model was used to predict the implosion times, final velocities, and kinetic energies listed in Table 1. In Figure 4 , the currents and implosion velocity are plotted for the 180 wire array with $8.9 \mu \mathrm{m}$ diameter wires (shot 2494). To estimate the maximum implosion velocities and kinetic energies, a 20:1 compression ratio was assumed. This ratio was based on the best measured for tungsten wire array implosions in the short-pulse Saturn mode.

The wire array implosions were studied with a suite of $\mathrm{x}$-ray diagnostics. The $\mathrm{x}$-ray output was measured using $1 \mu \mathrm{m}$ thick nickel bolometers [22] with nearly intrinsic resistivity values, which measured the total $x$-ray energy. Four filtered carbon cathode $x$-ray diodes (XRD) [23] provide time-resolved power estimates in four different energy ranges: $180-280 \mathrm{eV}, 280-470 \mathrm{eV}, 470-700 \mathrm{eV}$, and 800-150 eV. Based on the calibration of XRDs and the bolometers, we estimate the absolute measurement error to be $\pm 15 \%$ on the powers and yields. Another caveat on the measurement of energy 
and power, though, is that a simple treatment of the return cage geometry as a hohlraum would suggest that up to $10 \%$ of the measured power and energy may be due to re-radiation from the cathode surface and return cage.[9] Consequently, the power and energy numbers quoted here have a $+5 /-25 \%$ error bar, and they are quoted this way to be consistent in method with the numbers given in Reference 7.

The spatial extent of the radiating pinch was measured with a twelve-frame pinhole camera (SFPHC), filtered to detect $x$-rays with energies greater than $800 \mathrm{eV}$. Two of the twelve frames were timeintegrated, operating at two different gain levels. The remaining ten frames were time-resolved, with a 3 ns interframe time and 1 ns gating pulses. The 2:1 demagnification, combined with $50 \mu \mathrm{m}$ diameter pinholes, gave spatial resolution of approximately $180 \mu \mathrm{m}$. The bolometer, XRD array, and the time-resolved pinhole camera have all been previously fielded on Saturn.[7]

\section{25-mm-diameter Tungsten wire array results.}

In Table 2, the measured parameters for all the tungsten wire array shots are listed. These parameters include the times to the start and peak of the $x$-ray pulse, the $x$-ray power and energy, the $x$-ray pulse FWHM, the risetime and falltime of the $x$-ray pulse, and the measured plasma diameters (time-integrated and at the time of peak power). The measured load current, MITL current, and x-ray power are shown in Figure 5 for shot 2494. This shot consisted of a 180 wire array with $8.9 \mu \mathrm{m}$ diameter wires, i.e. a mass loading of 2160 $\mu \mathrm{g} / \mathrm{cm}$. The $\mathrm{x}$-ray power for shot 2494 was $37 \mathrm{TW}$ and the radiated energy was $680 \mathrm{~kJ}$. The FWHM of the $\mathrm{x}$-ray pulse was $13.5 \mathrm{~ns}$, however, the risetime was only 6 ns but the fall time was a much longer at $26.5 \mathrm{~ns}$. All the long pulse experimental $x$-ray pulses were more triangular than Gaussian in shape, which will be discussed in more detail in this section as it relates to post-stagnation heating 
mechanisms and to the dynamics seen in the time-resolved pinhole photography.

The calculated implosion time of 162 ns (see Table 1) for shot 2494 agrees well with the measured times to the start (162 ns) and peak (165 ns) of the x-ray power pulse. As illustrated by Figure 6 , the measured times to the start and peak of the $x$-ray pulses (circles and triangles) generally show good correlation with the circuit model predicted implosion times (dashed line). The $6140 \mu \mathrm{g} / \mathrm{cm}$ array, shot 2497, had measured times that were much greater than the calculated implosion time. This fact, coupled with the measured load current (Table 2) being lower than predicted (Table 1), suggests that an arc or other additional current loss occurred in shot 2497.

It is interesting to note that the measured load currents and MITL currents were very similar for all the shots, an example being shown in Figure 5 for shot 2494. This suggests that the convolute had very low electron losses as predicted by the circuit model calculations. Indeed, the observation of the implosion dip, associated with the stagnation of the array plasma, in the MITL currents is further confirmation of the high degree of insulation in the convolute. In contrast, the dip in the MITL currents has never been observed in the short-pulse mode, where the voltages are higher. Circuit model calculations indicate that the voltages at the convolute are only 400 $\mathrm{kV}$ during the initial current rise in the long pulse mode. Such low voltages make the magnetic insulation more effective, thereby reducing losses due to vacuum electron flow. Particle-in-cell calculations of these results will be the subject of a future paper. The good insulation of the convolute in the long-pulse mode permits the z-pinch to draw energy from the magnetic fields upstream of the convolute.

The tungsten wire arrays on Saturn radiated very effectively in the long pulse mode. The results of the variation in array mass for the $25 \mathrm{~mm}$ diameter arrays are shown in Figure 7, where the load currents and $x$-ray powers are plotted. Clearly, the current pulse for 
the most massive array is inconsistent with the other current profiles, and with the circuit model predictions in Table 1, again, suggesting that an arc or loss occurred. This powerflow problem certainly caused the radiated power and energy to be low, and because of this the energy and power data for shot 2497 will be omitted from the following plots. Figure 7 illustrates that as the array mass was increased, the peak of the load current prior to implosion increased, and the $\mathrm{x}$-ray power decreased. Again, the powers and energies from the longest implosion time shot are probably lower than if there had been no arc. Generally, the reduced $\mathrm{x}$-ray powers with increased implosion time were a consequence of broadening of the pulsewidth, however, rather than any decreased energy coupling. In fact, the total $x$-ray energy (the circl;e symbols in Figure 8(a)) increased slightly as the implosion time increased from 150 to $200 \mathrm{~ns}$ but then decreased at the longest implosion time, probably due to the loss. The increase in radiated energy is consistent with the larger load currents measured prior to stagnation for the more massive loads.

Calculations of the kinetic energy with a zero dimensional implosion model, shown as the dashed line in Figure 8(a), indicated that the kinetic energy should double from $150 \mathrm{~kJ}$ to $300 \mathrm{~kJ}$ as the implosion time varies from 130 to 230 ns. Two-dimensional MHD calculations of the implosion kinetic energy predict lower kinetic energies as shown by the dash-dot line in Figure 8(a). Previously, Deeney et al [7] and Peterson et al [17] have shown that measured radiated energies are approximately twice the calculated kinetic energies. In reference 17 , it was shown that the source of the additional radiation energy was heating of the stagnated plasma by pdV work and ohmic heating. In the experiments reported here, the ratio of radiated energy to the $0-D$ calculated kinetic energy is approximately 3.5 . This large ratio may result from the fact that energy is still be supplied to the vacuum section while the stagnation of the plasmas are occurring, coupled with the fact that the convolute is well insulated so a larger magnetic energy reservoir is available. Future calculations will examine the energy flow in the implosions in more 
detail, however, based on the long fall times and the dynamics as measured by the pinhole photography, the previous explanation seems plausible. Indeed, if one measures the energy radiated up to the time of peak power, see the data points denoted by triangles in Figure $8(a)$, then one finds that this energy is relatively constant and is in agreement with the calculations of the kinetic energies.

Figure 9 illustrates the trends observed in $x$-ray pulsewidth (FWHM), risetime and falltime for all the long implosion tungsten shots. The FWHMs (circles) and falltimes (squares) of the $\mathrm{x}$-ray pulses increase as the implosion time was increased from 130 to 250 ns (Figure 9(a)). Surprisingly, the FWHM and falltime measured on the 300 wire shot are similar to those for the equivalent 180 wire shot, whereas the risetime for the 300 wire array load was reduced by $30 \%$ (Fig. 9(b)). Also interesting to note is that the risetime increased as the implosion time increased from 130 to $170 \mathrm{~ns}$, but then remained nearly constant at 6 to $6.5 \mathrm{~ns}$, even for the $250 \mathrm{~ns}$ implosiōn time.

Increasing the number of tungsten wires from 180 to 300 increased the $\mathrm{x}$-ray power between 5 to $14 \%$ over similarly massed 180 wire arrays. The measured radiated energy and power for the 300-wire array are shown as the open symbols in Figure 9. The relatively small increase in power for a $65 \%$ increase in wire number is consistent with the wire number scan reported in Ref. 7 . In addition, as illustrated in Figure 10, the radiated x-ray pulses for the 180 and 300 wire equivalent mass cases were not substantially different. The overlay of the normalized powers in Figure 10(b) suggests that the 300 wire array produced a faster risetime without significantly changing the overall pulse shape.

The shortness of the risetimes implies that the imploding sheath was very uniform and narrow in the radial direction, despite the relatively slow implosion velocities. For example, the 300 wire case had a 4.5 ns risetime but an implosion velocity of only $35 \mathrm{~cm} / \mu \mathrm{s}$. Following the sheath thickness and thermalization time arguments of 
Section I, this risetime would suggest a characteristic thickness of 1.5 $\mathrm{mm}$ or less. The hypothesis is supported by time-resolved pinhole photographs. In Figure 11, two time-integrated images, and ten time-resolved images are shown for Shot 2519. These images are filtered to detect $\mathrm{x}$-rays above $800 \mathrm{eV}$ and the frame at $175 \mathrm{~ns}$, corresponds to the time of peak $x$-ray power. From the radial FWHMs, Figure 12, it is apparent that a tight compression was achieved, i.e. about $1 \mathrm{~mm}$ in diameter or a compression ratio of better than 25. A small plasma diameter is typically associated with a well-formed, narrow sheath. The plasma is observed to compress until peak power. After the minimum compression, the lengthaveraged FWHMs (circles) and the average plasma diameters (diamonds) diverge in value because of the development of an $m=1$ instability that is seen in the images in Figure 11.

In summary of the experimental data, these long implosion results are comparable to the best results, in terms of powers, pulsewidths, and plas̄ma dimensions, from tungsten wire array implosions in the Saturn short-pulse mode, as will be discussed in the next section.

\section{A comparison of tungsten wire array implosions on Saturn in the long and short pulse modes.}

Comparisons can be made between the long implosion tungsten results described in Section III and previous short implosion tungsten results obtained on Saturn [7] to place the long pulse results in context. Table 3 summarizes the best short pulse results obtained from tungsten wire array loads on Saturn. The excellent performance of the long implosion time loads on Saturn is clearly illustrated in figure 13, where the current and $\mathrm{x}$-ray power measured for a long implosion time shot, 2498 (solid lines), are overlaid with those for short implosion time shot, 2217 (dashed lines). The long implosion load, even though it had a substantially lower implosion velocity, produced a similar $x$-ray power to the short implosion load. Due to the power-flow and the pulsed power 
operation, the long-pulse shot had a $17 \%$ higher peak current than the short-pulse shot. Moreover, the long implosion load radiated $75 \%$ more energy than the short implosion load in part due to the higher currents. Most of this additional energy is radiated at late time, as shown in Figure 14, which depicts the normalized powers for shots 2217 and 2498. Shot 2217 has been shifted in time to overlay the pulses. Figure 13 shows almost identical initial risetimes for the two shots, but that the long implosion shot has a much longer falltime. This effect is consistent with on-axis heating [17], and will be the subject of investigation by $2-D$ radiation-magnetohydrodynamic calculations.

Following the sheath thickness arguments in the introduction, the shell thicknesses must have been equivalent, and possibly thinner for the long implosion shot, since the risetimes are very similar for 2217 and 2498. Comparison of the $x$-ray pinhole images, shown in Figure 14, shows that, indeed, the implosion qualities were very similar. - The time-integrated images in Figure 15 reveal that both shots produced millimeter diameter, straight pinches. The difference in visible length is due to geometric differences of the return cages. The more quantitative comparison of intensity profiles seen in Figure 16 clearly illustrates that the radial lineouts (Figure 16(a)) have the same spatial FWHM, $0.9 \mathrm{~mm}$. The axial lineouts (Figure 16(b)) show intensity modulations with similar spatial wavelengths and amplitudes for both shots as well, except for the localized, bright emission seen in the image for shot 2217 at $z=10 \mathrm{~mm}$.

It is surprising that the long implosion wire arrays appear to have similar implosion quality than the short implosion ones, considering that the long-implosion arrays were imploding from a $25 \mathrm{~mm}$, i.e. twice the diameter of the arrays used in the short pulse mode. Another measure of the implosion quality that can be used to evaluate the relative performance of long-pulse vs. short pulse is the $\mathrm{x}$-ray pulse risetime. This risetime is plotted versus the implosion velocity in Figure 17, where the long-pulse 180 wire array data are denoted by solid-circle symbols, and the long-pulse 300-wire array 
is denoted by open-circle symbols. The short-pulse data, taken from Table 3, are marked as solid-triangle symbols. The short-pulse data shows a similar trend to the long-pulse data, with the pulsewidth decreasing with increasing implosion velocity. Interestingly, the long implosion shot produced a faster risetime than the short implosion shot for the same velocity $(50 \mathrm{~cm} / \mu \mathrm{s})$ calculated using a zero dimensional implosion model. Both of these shots had similar interwire separation ( 0.56 vs $0.45 \mathrm{~mm}$ ), a characteristic suggested as a possible parameter in determining the $x$-ray power from wire array implosions.[8]

\section{Two-dimensional MHD and heuristic calculations}

Future work will look at the implosions in more detail using twodimensional radiation-MHD calculations but it is instructive to consider such calculations for the two comparable velocity implosions, 2217 and 2496. Assuming that RT growth was the dominant physics in determining the measured risetime, a series of two-dimensional MHD calculations were performed to match the measured risetimes by varying only the initial random density perturbation. The two-dimensional MHD code, Mach2,[24] was employed with SESAME EOS, resistivity tables, with an emission radiation model, and with $100 \mu \mathrm{m}$ cell size in both the axial and radial directions. Iso-density contour plots are depicted for the calculations that best matched the measured risetimes in Figure 18. In the case of shot 2217 , the predicted risetime was still lower than the measured value. From Figure 18, it is apparent that to match the measured risetimes, the calculations would indicate that prior to stagnation, the long implosion case had a narrower shell than the short implosion case, but both had similar RT mode structure, i.e (wavelengths). Since the long implosion case implodes from twice the initial diameter, there is a significant difference in the initial perturbation levels needed to get these matches. Specifically, a $4 \%$ perturbation was used in the long pulse case compared to a $40 \%$ in 
the short pulse case. The question arises, therefore, why were the initial conditions so different.

It had been previously suggested that the degree of overlap of the wire explosion phase and the wire array implosion phase is important in determining the radiative performance of wire arrays.[20] For the long implosion shots reported in this paper, the arrays have 50 to 100 ns to explode prior to acceleration to the axis. This could permit the wires to expand, thereby reducing axial and radial asymmetries prior to the implosion phase. To quantify the decrease in risetime for the long implosion, a heuristic model [25] which has been used to study wire number effects with aluminum implosions can be employed. In this model, initial expansion of the individual wires and the associated instability growth are considered. The level of the instability growth and the statistical averaging of these instabilities over the wire number determine an average perturbation at the time when the wires merge. This perturbation is used thēn to seed a Rayleigh-Taylor growth model. The time of the wire merger $\left(t_{m}\right)$ depends strongly on the inter-wire separation and the expansion velocity of the wires. The latter quantity is a function basically of the wire material, and it is determined from individual wire explosion experiments,[26] and from laser diagnostics of wire arrays.[27] The single wire and array experiments both measure an average expansion velocity of 0.7 to $0.9 \mathrm{~cm} / \mu \mathrm{s}$. The initial conditions for the acceleration phase therefore depends on the ratio of the growth time of the individual wire $\mathrm{m}=0$ instabilities, the merger time $\left(t_{m}\right)$ and the number of wires as given by equation 30 in Ref. 25 .

If the merger time is normalized to the implosion time $\left(t_{p}\right)$ then $t_{m} / t_{p}$ can be plotted versus array mass, see Figure 19. As the mass increases hence the implosion time increases and the ratio $\mathrm{tm} / \mathrm{tp}$ decreases from 0.3 to 0.16 . Indeed for the longest implosion times, $t_{m} / t_{p}$ is much less than the normalized time before the wire array reaches an implosion velocity of $2 \mathrm{~cm} / \mu$ s, i.e. the beginning of the acceleration phase where RT will grow. This normalized quantity does not depend strongly on the implosion time, and it is shown as 
the dashed line in Figure 19. For comparison, in the short pulse mode, $t_{m} / t_{p}$ is about 0.9 , which is consistent with laser shadowgraphy measurements on Saturn [26] that showed the wires still not merged at 0.6 of the implosion time. This observation also suggests that a shell based model would have difficulty in matching the experimental measurements, therefore the $40 \%$ density seed could reflect a difference in implosion physics rather than a physical initial condition. As cited above, Whitney et al [20] discussed a similar issue when comparing the dependence of aluminum $\mathrm{K}$-shell production between the 50-ns, 8-MA Saturn generator and the 100 ns, 4-MA Double-EAGLE generator. It was pointed out that the overlap between the explosion and implosion phases was greater with the faster risetime Saturn generator. This observation led directly to the increased wire number experiments on Saturn.[28,7,8]

Using this heuristic model, the calculated risetimes versus array mass are plotted in Figure 20 for the 180 and 300 wire arrays. There is reasonable agreement although the calculated values are generally longer than those measured experimentally. An absolute agreement should not be expected due to the limitations in the assumptions required to develop an analytical theory of such a complex issue. The heuristic model however produces some of the trends: the increase in risetime with increased implosion time; and the decrease in risetime with the higher wire number. The absolute differences are due to limitations of the model i.e. the lack of Rayleigh-Taylor, sheath and radiation physics. The differences in the trends could be again due to the some deficiencies in the model. Nevertheless, the heuristic model indicates that the short risetimes are achieved because the development of the $m=0$ instabilities on the individual wires are terminated well before the acceleration phase.

\section{Conclusions.}

The comparison between the short-pulse mode and long-pulse mode tungsten wire array implosions on Saturn suggests that by careful 
load design and fabrication, implosion times of up to $200 \mathrm{~ns}$ can be achieved without a significant penalty in radiated $x$-ray power.

Indeed, these experiments have shown that a $25 \mathrm{~mm}$ diameter, 170 ns implosion time load can produce $43 \mathrm{TW}$. This compares favorably with the previously achieved $40 \mathrm{TW}$ produced by a $12.5 \mathrm{~mm}$ diameter, 50 ns implosion time load. Future experiments and modeling are needed to optimize the power from these loads on Saturn and on the 20-MA Z accelerator in the long-pulse mode. Nested wire arrays [11,29] could increase the radiated powers and larger diameter, higher velocity implosions should be pursued for dynamic hohlraum applications. For vacuum hohlraum applications, experiments and modeling of smaller diameter, lower velocity implosions, which allow the area of the hohlraum walls to be minimized, need to be performed.

We would like to thank John McGurn, Dan Jobe, John McKenney, Brad Peyton, the Saturn crew and the wire array fabrication teams at SNL for their outstanding technical support. We also express our gratitude to Dr. Ralph Schneider of the Defense Threat Reduction Agency who encouraged and supported the initial long implosion experiments with argon and aluminum. Sandia is a multi-program laboratory operated by Sandia Corporation, a Lockheed Martin Company, for the United States Department of Energy under Contract DE-AC0494 AL 85000 . 


\section{References.}

1. J.H. Degnan, W.L. Baker, K.E. Hackett, et al, IEEE Trans. Plasma Sci. PS-15; 635, (1987).

2. D.L. Peterson, R.L. Bowers, J.H. Brownell, A.E. Greene, K.D. McLenithan, T.A. Oliphant, N.F. Roderick, and A.J. Scannapieco, Phys. Plasmas 3, 368, (1996).

3. C. Deeney, P.D. LePell, I. Roth, et al, J. Appl. Phys. 72, 1297, (1992).

4. R.C. Commisso, J.P. Apruzese, D.C. Black, et al, IEEE Trans. Plasma Sci. 26, 1068, (1998).

5. V.P. Smirnov, Plasma Phys. Controlled Fusion 33, 1697, (1991).

6. J. Brownell, R,L. Bowers, K.D. McLenithan, and D.L. Peterson, Phys Plasmas. 5, 2071, (1998).

7. C. Deeney, T.J. Nash, R.B. Spielman, et al., Phys. Rev. E 56, 5945, (1997).

8. T. W. L. Sanford, G.O. Allshouse, B.M. Marder, et al, Phys. Rev. Lett. 77, 5063, (1996).

9. R.B. Spielman, C. Deeney, G.A. Chandler, et al, Phys. Plasmas 5, 2105, (1998).

10. C. Deeney, D.L. Peterson, R.B. Spielman, et al, Phys. Plasmas 5, 2605, (1998).

11. C. Deeney, M.R. Douglas, R.B. Spielman, et al, Phys. Rev. Lett., 81, 4883, (1998).

12. T.W. Hussey, N.F. Roderick, U. Shumlak, R.B. Spielman and C. Deeney, Phys. Plasmas 2, 2055, (1995).

13. S.M. Golíberg and A.L. Velikovich, Phys. Fluids B 5, 1164, (1993).

14. A.L. Velikovich, F.L. Cochran and J. Davis, Phys. Rev. Lett 77, 853, (1996).

15. M.R. Douglas, C. Deeney and N. Roderick, Phys. Rev. Lett. 78, 4577, (1997).

16. J.H. Hammer, J.L. Eddleman, P.T. Springer, M. Tabak, A. Toor, K.L. Wong, C. Deeney, R. Humphreys, T.J. Nash, T.W.L. Sanford, R.B. Spielman, \& J.S. DeGroot, Phys. Plasmas 3, 2063, (1996).

17. D.L. Peterson, R.L. Bowers, K.D. McLenithan et al, Phys. Plasmas 5, 3302, (1997). 
18. C. Deeney, P.D. LePell, B.H. Failor, S.L. Wong, J.P. Apruzese, K.G. Whitney, J.W. Thornhill, J. Davis, E. Yadlowsky, R.C. Hazelton, J.J. Moschella, T.J. Nash \& N. Loter, Phys. Rev. E 51 (5-B), 4823, (1995).

19. I.K. Aivazov, V.D. Vikarev, G.S. Volkov, L.B. Nikandrov, V.P. Smirnov, and V. Ya Tsarfin, Sov. J. Plasma Phys. 14, 110, (1988).

20. K.G. Whitney, J.W. Thornhill, P.E. Pulsifer, et al, Phys. Rev. E 56, 3540, (1997).

21. R. B. Spielman, R. J. Dukart, D. L. Hanson, B. A. Hammel, W. W. Hsing, M. K. Matzen, and J. L. Porter, “Dense Z-Pinches, Second International Conference" ed. by N. R. Pereira, J. Davis, and N. Rostoker, AIP Conference Proc. 195, 3 (1989).

22. R.B. Spielman, C. Deeney, J.S. McGurn, et al, "Fast Resistive Bolometery," to be published in Rev. Sci. Instrum 70, Januaury, (1999).

23. R.H. Day, P. Lee, E.B. Saloman, and D. Nagel, J. Appl. Phys. 52, 6965, (1981).

24. R.E. Peterkin, Jr. J.H. Degnan, T.W. Hussey, N.F. Roderick, and P.J. Turchi, IEEE Trans. Plasma Sci. 21, 552, (1993).

25. M.G. Haines, IEEE Trans. Plasma Sci. 26, 1275, (1998).

26. F.N. Beg, J. Ruiz, A.E. Dangor, E. Clark, \& I. Ross, Bull. Am. Phys. Soc. 42(10), 2051, (1997).

27. C. Deeney, J.S. McGurn, D. Noack, et al, Rev. Sci. Instrum. 68, Part II , 653, (1997).

28. C. Deeney, T.J. Nash, R.B. Spielman, Phys. Plasmas 5, 2431, (1998).

29. M.R. Douglas, C. Deeney, R.B. Spielman, N.F. Roderick, and D.L. Peterson, "Computational modeling of tungsten z-pinches with tuning layers," submitted to Phys. Rev. E. 
Table 1. Tungsten long implosion shot parameters.

\begin{tabular}{cccccccc}
\hline \hline & Wire & & & Calc. \\
Wire & $\begin{array}{c}\text { Diam. } \\
(\mu \mathrm{m})\end{array}$ & $\begin{array}{c}\text { Mass } \\
(\mu \mathrm{g} / \mathrm{cm})\end{array}$ & $\begin{array}{c}\text { Current } \\
(\mathrm{MA})\end{array}$ & $\begin{array}{c}\text { Timp } \\
(\mathrm{ns})\end{array}$ & $\begin{array}{c}\text { Energy } \\
(\mathrm{kJ})\end{array}$ & $\begin{array}{c}\text { Collapse } \\
\text { Velocity } \\
(\mathrm{cm} / \mu \mathrm{s})\end{array}$ & $\begin{array}{c}\text { Saturn } \\
\text { Shot } \\
\text { No. }\end{array}$ \\
\hline 180 & 5.1 & 710 & 6.2 & 122 & 170 & 48 & 2496 \\
180 & 7.5 & 1530 & 7.4 & 148 & 230 & 39 & 2495 \\
180 & 8.9 & 2160 & 7.8 & 162 & 260 & 35 & 2494,2520 \\
180 & 13 & 4609 & 8.8 & 199 & 316 & 26 & 2519 \\
180 & 15 & 6140 & 9.1 & 217 & 310 & 23 & 2497 \\
300 & 7.1 & 2300 & 7.9 & 165 & 270 & 35 & 2498 \\
\hline \hline
\end{tabular}


Table 2. Measured parameters for the 25-mm diameter tungsten wire arrays.

\begin{tabular}{|c|c|c|c|c|c|c|c|c|c|c|c|}
\hline $\begin{array}{l}\text { Shot } \\
\text { No. }\end{array}$ & $\begin{array}{c}\text { Mass } \\
(\mu \mathrm{g} / \mathrm{cm})\end{array}$ & $\begin{array}{l}\text { Load } \\
\text { Current } \\
\text { (MA) }\end{array}$ & $\begin{array}{c}\text { Tstart } \\
\text { (ns) }\end{array}$ & $\begin{array}{c}\text { Tpeak } \\
\text { (ns) }\end{array}$ & $\begin{array}{l}\text { Total } \\
\text { Energy } \\
(\mathrm{kJ})\end{array}$ & $\begin{array}{c}\text { Total } \\
\text { Power } \\
\text { (TW) }\end{array}$ & $\begin{array}{c}\text { X-ray } \\
\text { FWHM } \\
\text { (ns) }\end{array}$ & $\begin{array}{c}\text { X-ray } \\
\text { Rise } \\
\text { (ns) }\end{array}$ & $\begin{array}{c}\text { X-ray } \\
\text { Fall } \\
\text { (ns) }\end{array}$ & $\begin{array}{l}\text { T.I. } \\
\text { Dia. } \\
(\mathrm{mm})\end{array}$ & $\begin{array}{l}\text { T.R. } \\
\text { Dia. } \\
(\mathrm{mm})\end{array}$ \\
\hline 2496 & 710 & 5.8 & 128 & 132 & 600 & 49 & 7.5 & 4.0 & 22.5 & & \\
\hline 2495 & 1530 & 7.4 & 148 & 155 & 720 & 41 & 14.0 & 5.5 & 25.0 & 0.9 & \\
\hline 2494 & 2160 & 7.7 & 162 & 165 & 680 & 37 & 13.5 & 6.0 & 26.5 & 0.9 & 1.0 \\
\hline 2520 & 2160 & 7.8 & 165 & 170 & 760 & 42 & 15.5 & 6.5 & 30.0 & & \\
\hline 2519 & 4609 & 8.6 & 210 & 220 & 640 & 30 & 15.5 & 6.5 & 30.0 & 0.9 & 1.0 \\
\hline 2497 & 6140 & 8.4 & 248 & 255 & 470 & 20 & 19.0 & 6.0 & 36.0 & & \\
\hline $\begin{array}{l}2498 \\
(300)\end{array}$ & 2300 & 7.6 & 165 & 173 & 800 & 43 & 14.5 & 4.5 & 28.0 & 0.9 & 1.0 \\
\hline
\end{tabular}


Table 3. Measured parameters for the short implosion-time tungsten wire arrays.

\begin{tabular}{|c|c|c|c|c|c|c|c|c|c|c|c|}
\hline Shot & $\begin{array}{l}\text { Diam } \\
(\mathrm{mm})\end{array}$ & $\begin{array}{l}\text { Wire } \\
\text { No. }\end{array}$ & $\begin{array}{c}\text { Mass } \\
(\mu \mathrm{g} / \mathrm{cm})\end{array}$ & $\begin{array}{l}\text { Load } \\
\text { Current } \\
\text { (MA) }\end{array}$ & $\begin{array}{c}\text { Tpeak } \\
\text { (ns) }\end{array}$ & $\begin{array}{c}\text { Total } \\
\text { Energy } \\
(k J)\end{array}$ & $\begin{array}{l}\text { Total } \\
\text { Power } \\
\text { (Tw) }\end{array}$ & $\begin{array}{c}\text { X-ray } \\
\text { FWHM } \\
\text { (ns) }\end{array}$ & $\begin{array}{c}X \text {-ray } \\
\text { Rise } \\
\text { (ns) }\end{array}$ & $\begin{array}{c}\text { T.I. } \\
\text { Diam } \\
(\mathrm{mm})\end{array}$ & $\begin{array}{l}\text { T.R. } \\
\text { Diam } \\
(\mathrm{mm})\end{array}$ \\
\hline 2217 & 12.5 & 70 & 610 & 6.4 & 60 & 400 & 40 & 8.5 & 5.5 & 0.7 & 1.0 \\
\hline 2224 & 17.5 & 120 & 450 & 6.6 & 50 & 450 & 75 & 4.0 & 3.5 & 0.9 & 1.1 \\
\hline
\end{tabular}




\section{Figure Captions.}

Figure 1. A cut-away schematic of the Saturn waterline pulsed power generator is shown in (a). The pulse forming lines, called "line-ones", were shorted for these experiments. Voltage waveforms are shown in (b) and (c) for the short-pulse and long-pulse modes of Saturn.

Figure 2. The measured load current into a $2 \mathrm{~cm}$ long, $25 \mathrm{~mm}$ diameter, short circuit load.

Figure 3. (a) A photograph of a $25 \mathrm{~mm}$ diameter with 180 tungsten wires. Vacuum baking and gold coatings were employed to minimize plasma closure in the $3.75 \mathrm{~mm}$ coaxial feed gaps.

Figure 4. The MITL current, load current, and implosion velocity calculated with a $0-D$ implosion model coupled to a circuit model for an initial mass of $2160 \mu \mathrm{g} / \mathrm{cm}(180,8.9 \mu \mathrm{m}$ dia. W wires).

Figure 5. The measured MITL current, load current and x-ray power for a $25 \mathrm{~mm}$ dia., 180 wire array long implosion time shot. This shot (2494) had $8.9 \mu \mathrm{m}$ dia. wires.

Figure 6. The measured times to the start of the $x$-ray pulse (circles) and to the peak of the $x$-ray pulse (triangles) versus the initial array mass. The circuit model predicted implosion time is shown as a dashed line. The open circle and triangle are for the 300 wire shot.

Figure 7. The variations in load currents and $x$-ray powers for all the 180 wire arrays in this series.

Figure 8. Plots of (a) the radiated energy versus implosion time, and (b) the radiated power versus implosion time. The open symbols are for the 300 wire case and the circuit model calculated kinetic energy, for a 20:1 compression ratio, is shown in (a) as a dashed line.

Figure 9. (a) The measured FWHM (circles) and falltime (squares) of the $x$-ray power pulses versus implosion time. (b) The measured risetime (triangles) of the $x$-ray pulse as a 
function of implosion time. The open symbols in both plots are for the 300-wire array data.

Figure 10. (a) A comparison of the $x$-ray powers from the 180 and 300 wire arrays with similar masses. (b) Overlay of the normalized radiation pulses where the 300 wire data has been shifted by -2 ns in time.

Figure 11. Two time-integrated (T.I.) and ten time-resolved filtered images, denoted by the time of the frame, from shot 2519 (180, $8.9 \mu \mathrm{m}$ diam. wires). The $12.5 \mu \mathrm{m}$ beryllium filter passes photons above $800 \mathrm{eV}$. The frame, at $175 \mathrm{ns,}$ corresponds to the time of peak power, and later time $\mathrm{m}=0$ and $\mathrm{m}=1$ instability development can be seen.

Figure 12. A plot of the measured x-ray power pulse with the plasma diameter versus time. The diameters are calculated using two methods, by taking an axially averaged value (circles) and by averaging the FWHM at each radial location (diamonds). The former method ... includes contributions due to radial displacements caused by $\mathrm{m}=1$ instabilities, whereas the latter method does not.

Figure 13. A comparison of the long implosion shot 2498 (300, 8.9 $\mu \mathrm{m}$ dia. wires) with a short implosion shot, shot 2217 (70, $12.5 \mathrm{~mm}$ dia. wires). Shot 2217 had an implosion velocity of $50 \mathrm{~cm} / \mu \mathrm{s}$ and produced a $8.5 \mathrm{~ns}, 40 \mathrm{TW}$ x-ray power pulse.

Figure 14. Overlay of the normalized power pulses for shots 2498 and 2217, illustrating the similar $x$-ray pulse risetimes, but noticeably different falltimes.

Figure 15. Time-integrated, $>800 \mathrm{eV}$ images from a 300 wire, 25 $\mathrm{mm}$ dia., long-pulse shot (2498) and a 70 wire, $12.5 \mathrm{~mm}$ dia., short-pulse shot (2217). The difference in lengths is due to the steep (35 degree to horizontal) viewing angle and different hardware geometries.

Figure 16. The tightness and axial uniformity of the two z-pinch images shown in Figure 14 are similar based on (a) radial, axially-integrated and (b) axial, radially-integrated intensity densitometer scans. 
Figure 17. The measured risetimes as a function of implosion velocity for the long-pulse 180 -wire loads (solid circles), the long-pulse 300-wire load (open circle) and two shortpulse-mode shots (triangles). The numbers in parenthesis depict the inter-wire spacing for the loads.

Figure 18. Iso-density contour plots at different times for (a) a short--pulse shot (2217) and (b) a long-pulse shot (2496). These calculations represent the best match to the measured risetimes, and the initial random density perturbations were 4 and $40 \%$ for 2496 and 2217 . respectively.

Figure 19. The time for wire array merger normalized to the time to pinch (solid circles) for the tungsten arrays using a heuristic model versus the initial mass. These times are less than those calculated for the wires to begin their acceleration (dashed curve). The 300-wire array data point (triangle) is less than the equivalently massed 180 - wire array.

Figure 20. A comparison of the risetimes predicted from the heuristic model with the measured risetimes. 
(a)

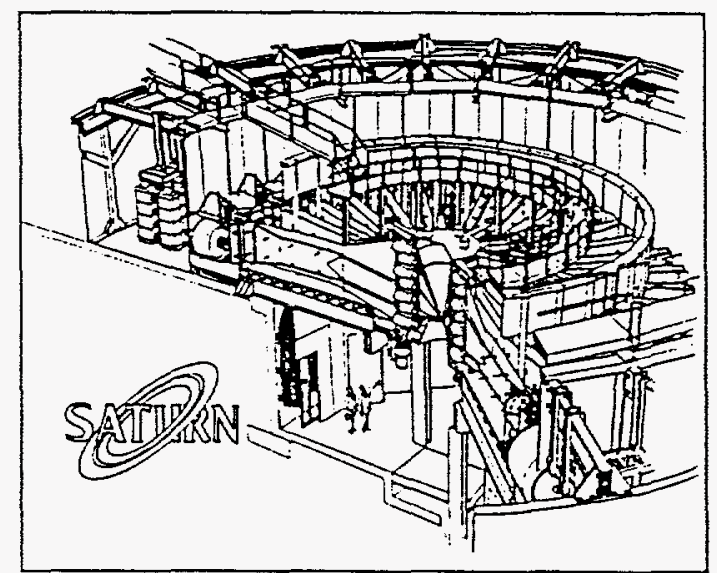

(b)

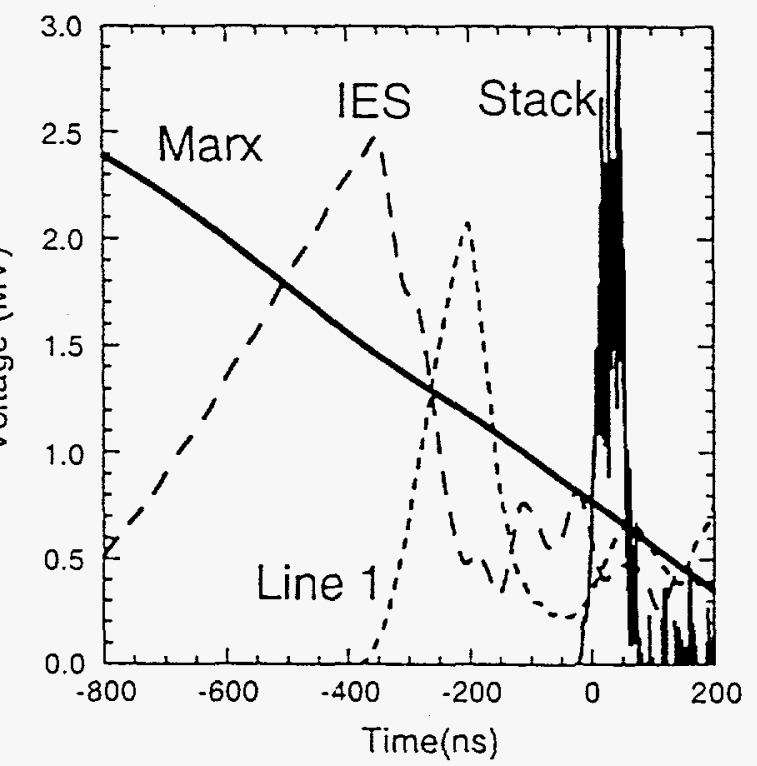

(c)

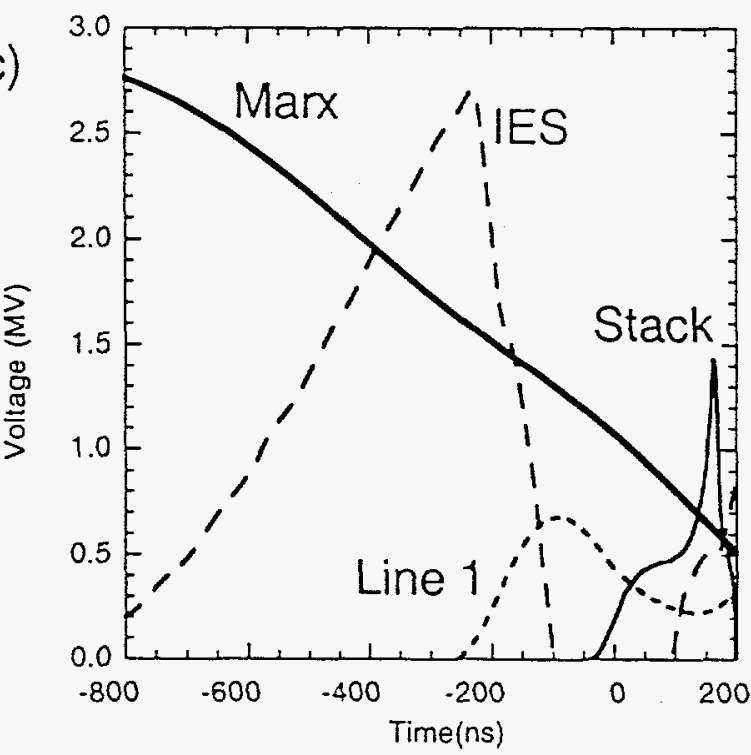

C. Deeney et al 


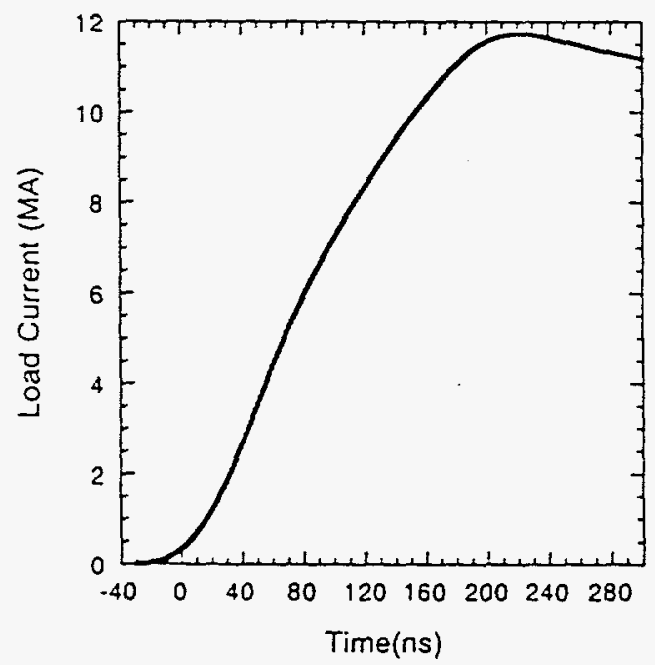

C. Deeney et al 


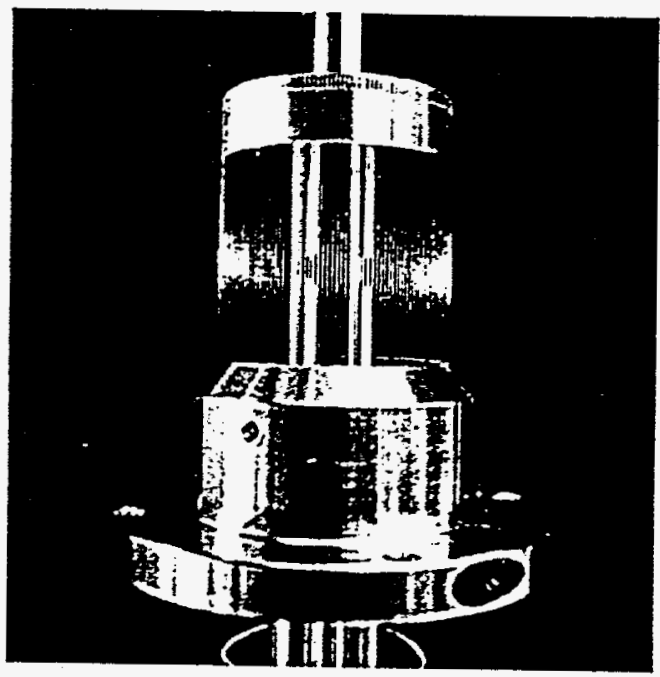

C. Deeney et al 


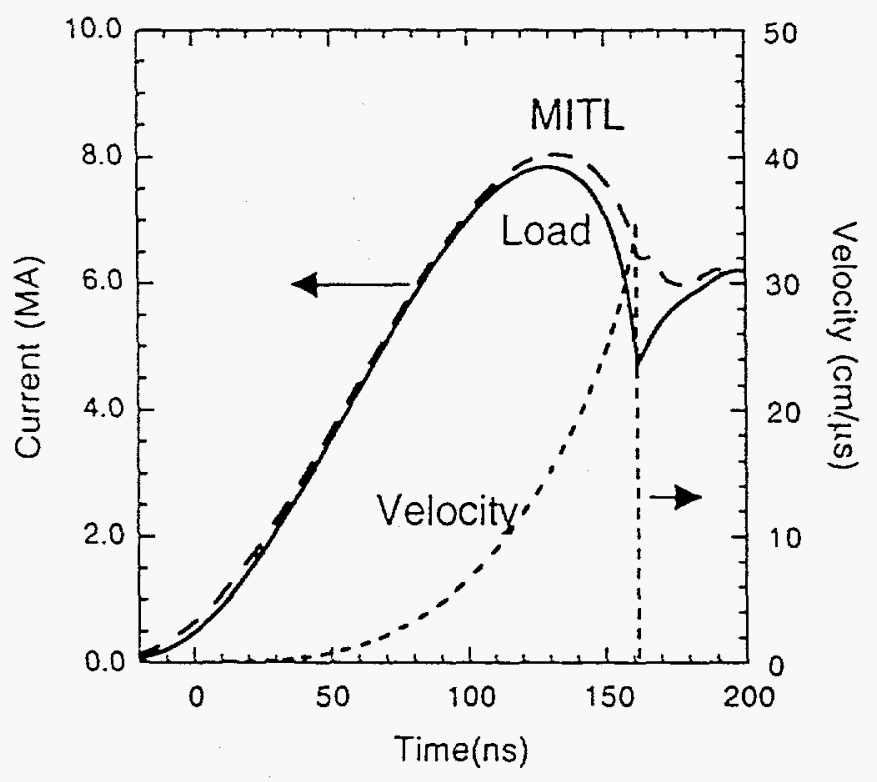

C. Deeney et al 


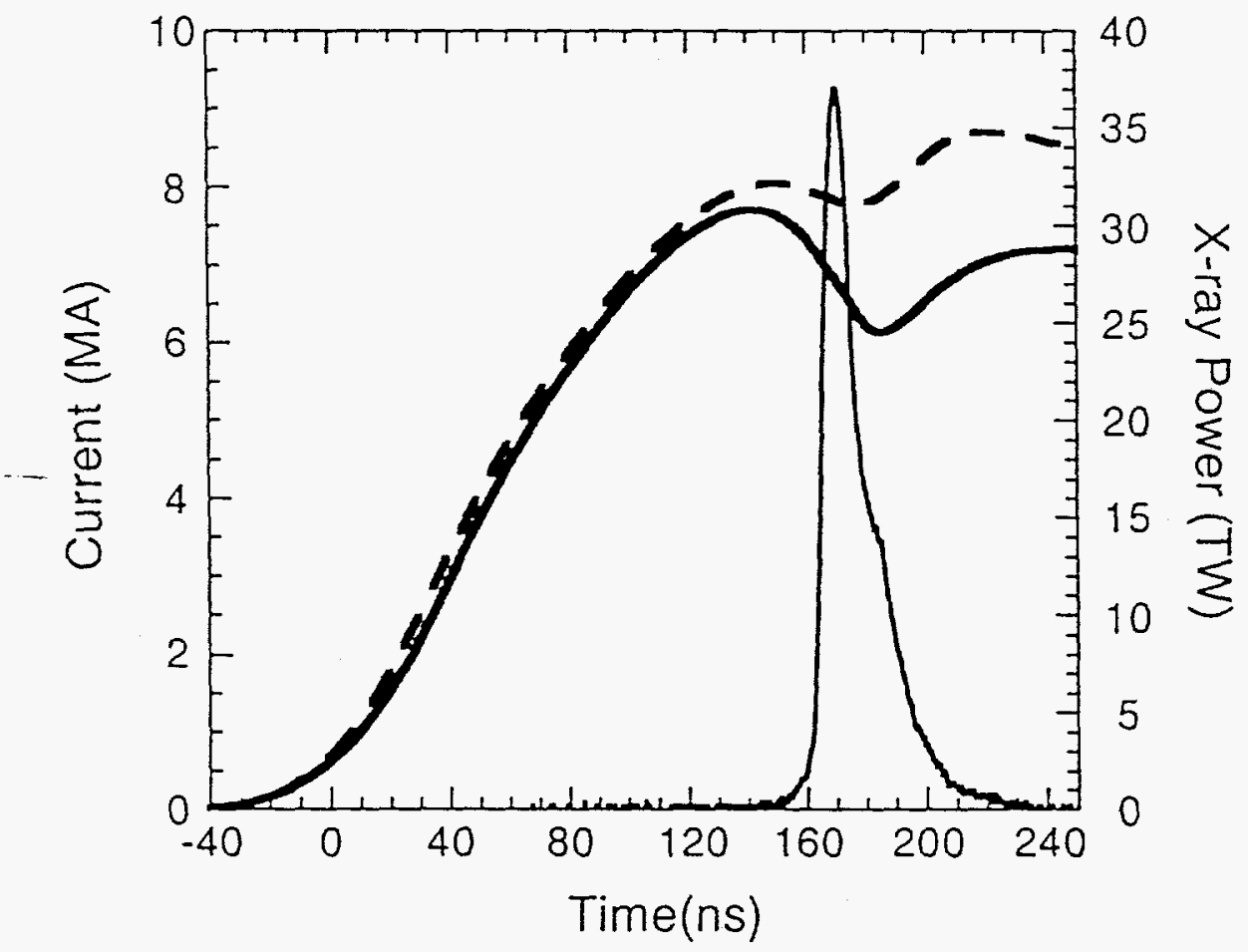

C. Deeney et al 


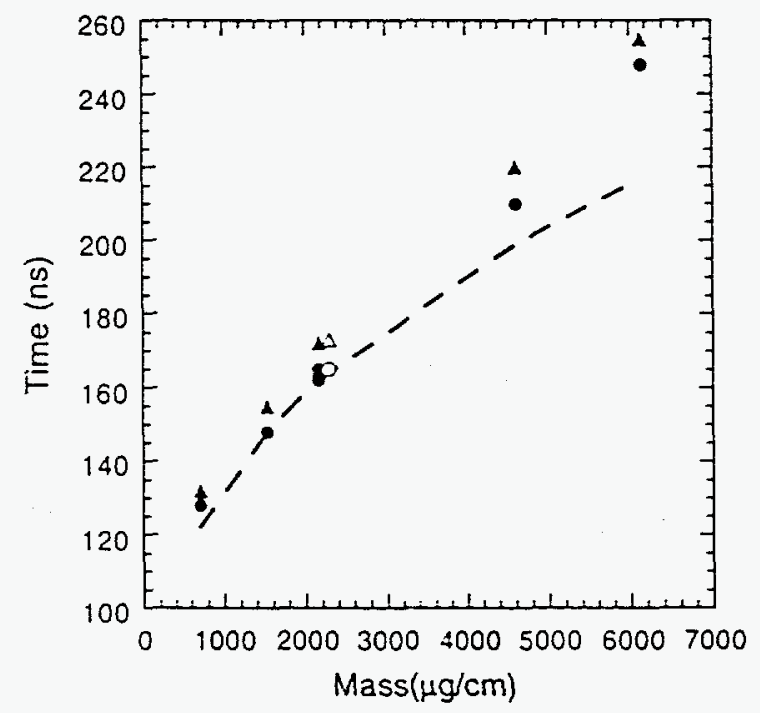

C. Deeney et al 


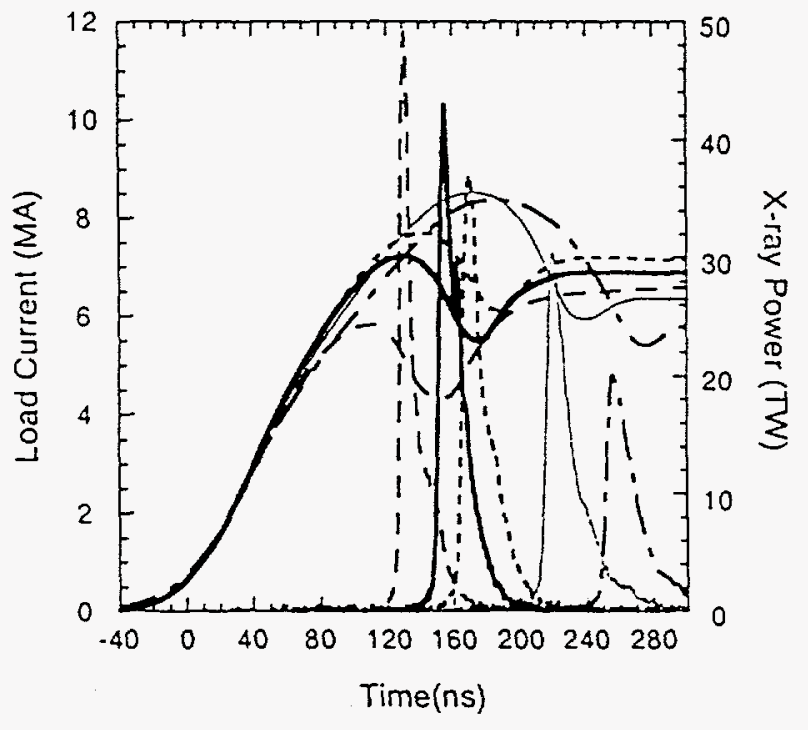

C. Deeney et al 

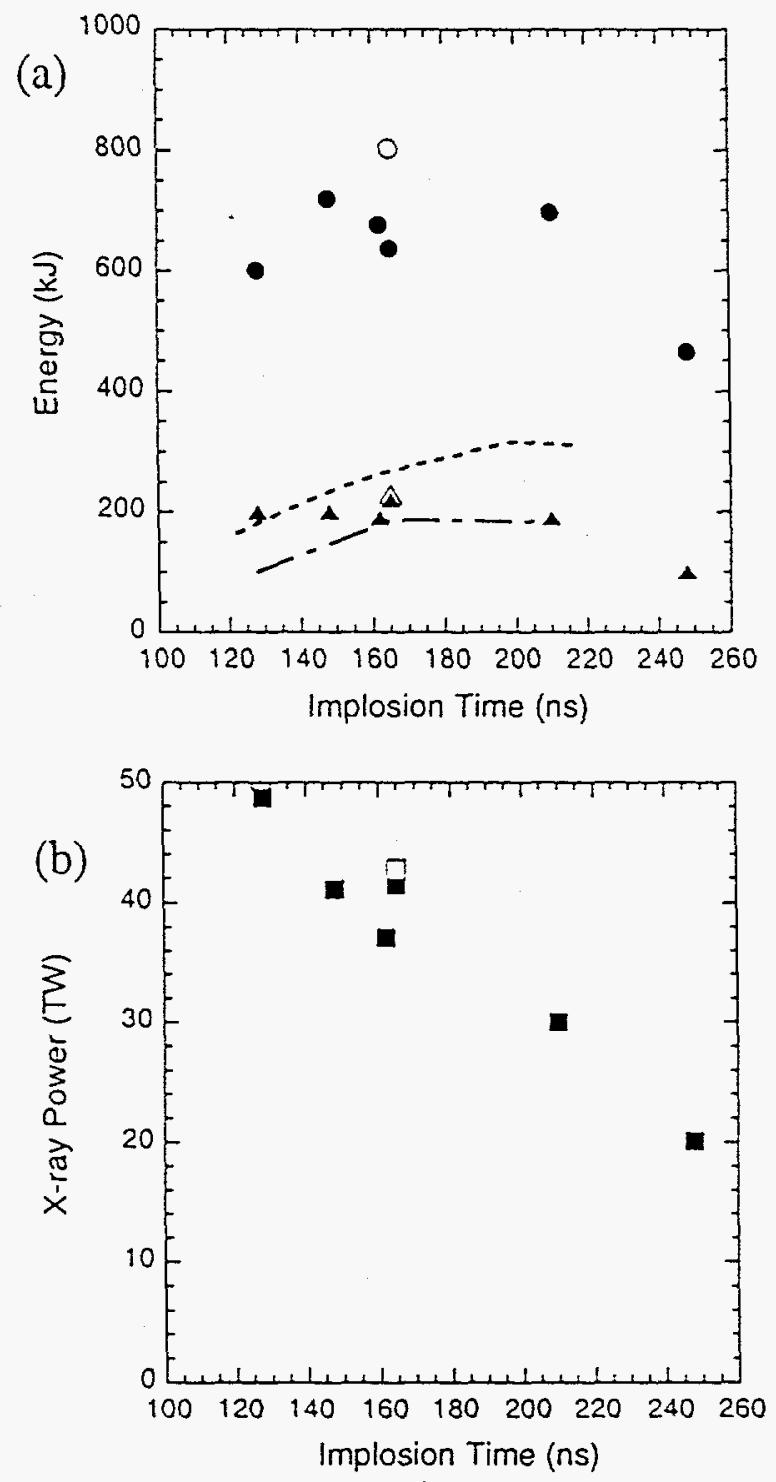

C. Deeney et al 

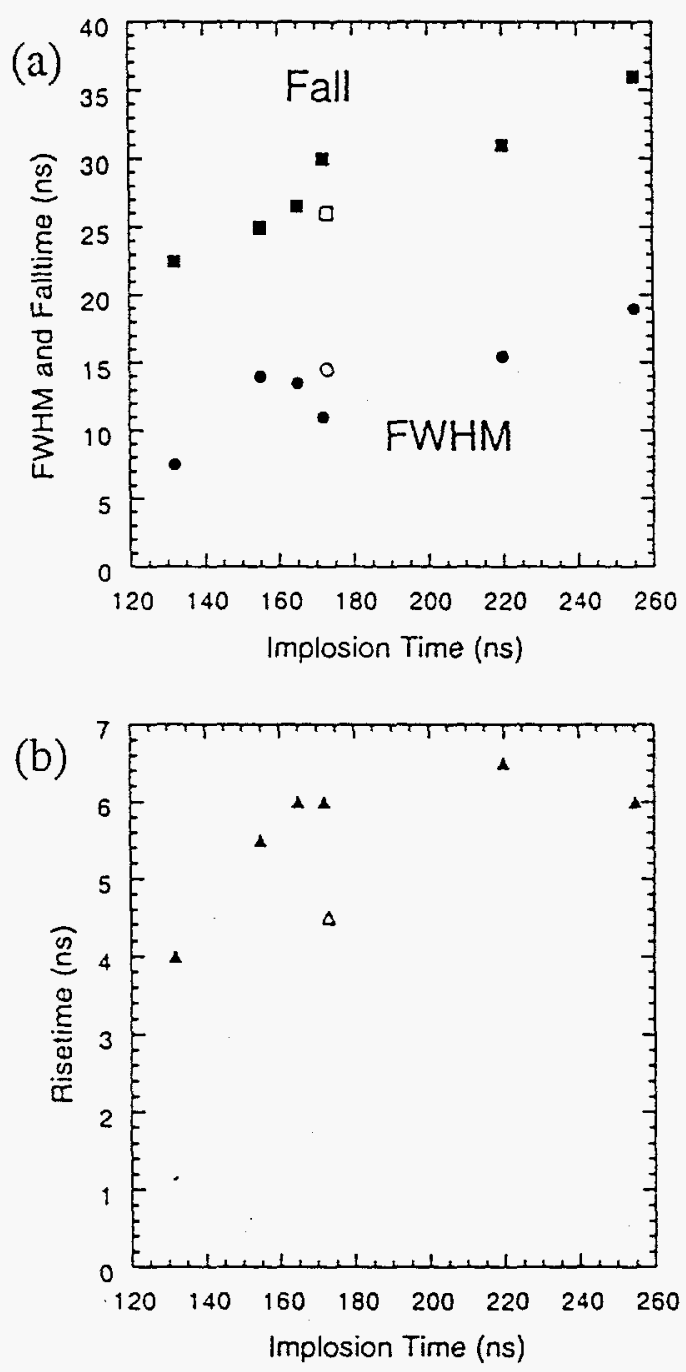

C. Deeney et al 

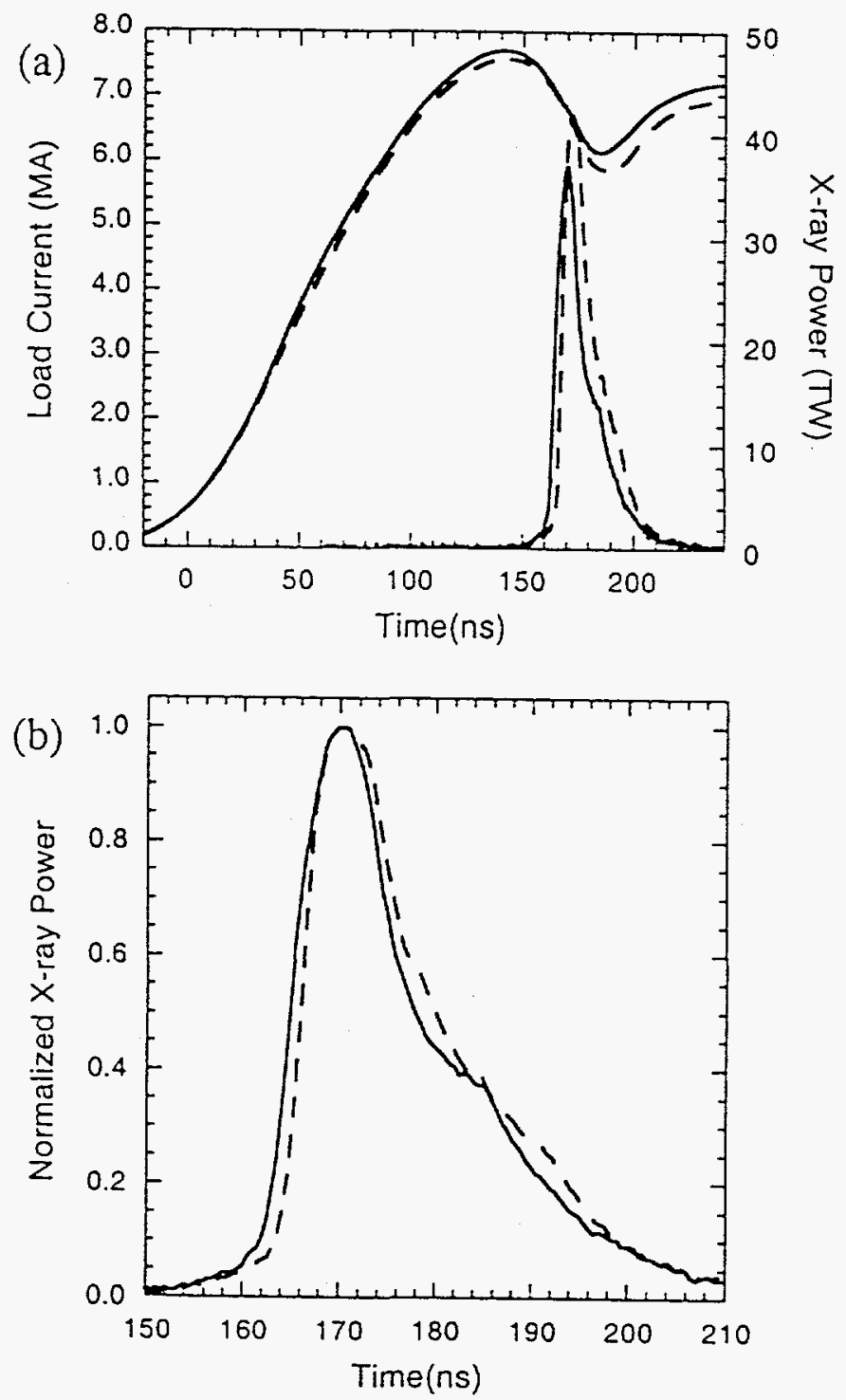

C. Deeney et al 


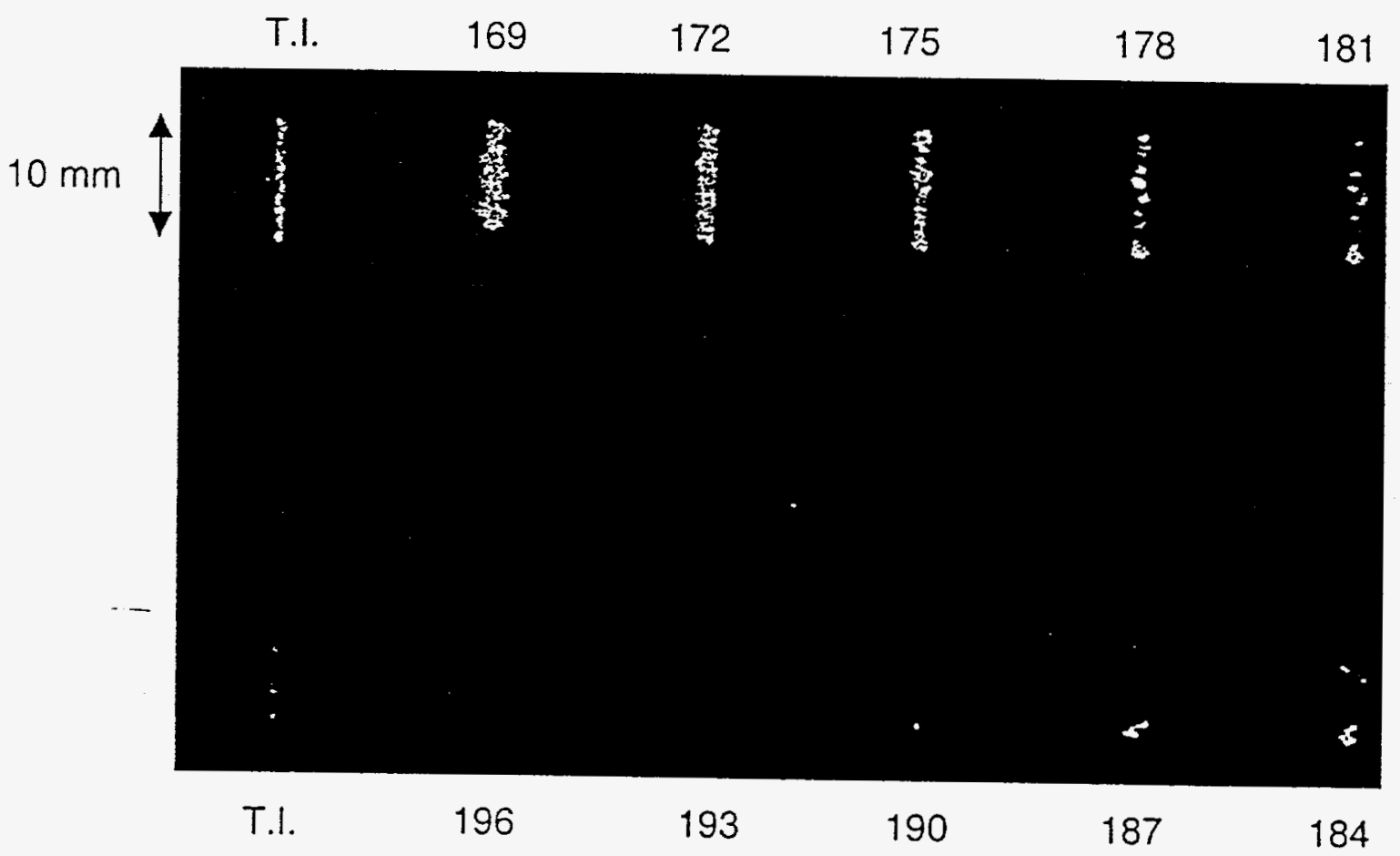

C. Deeney et al 


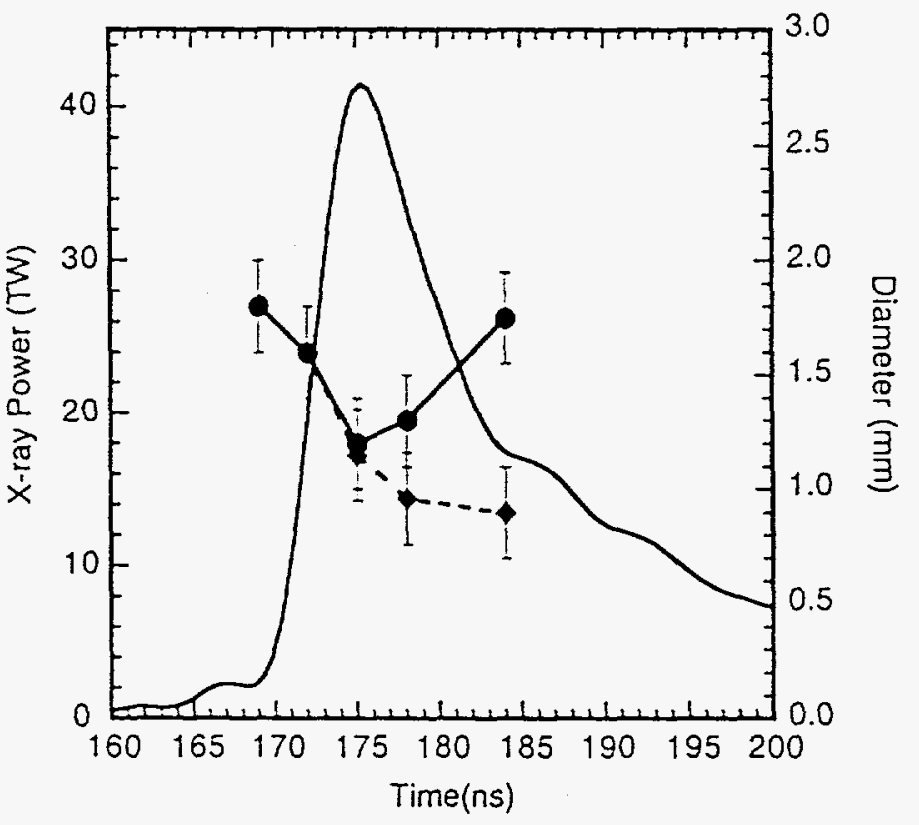

C. Deeney et al 


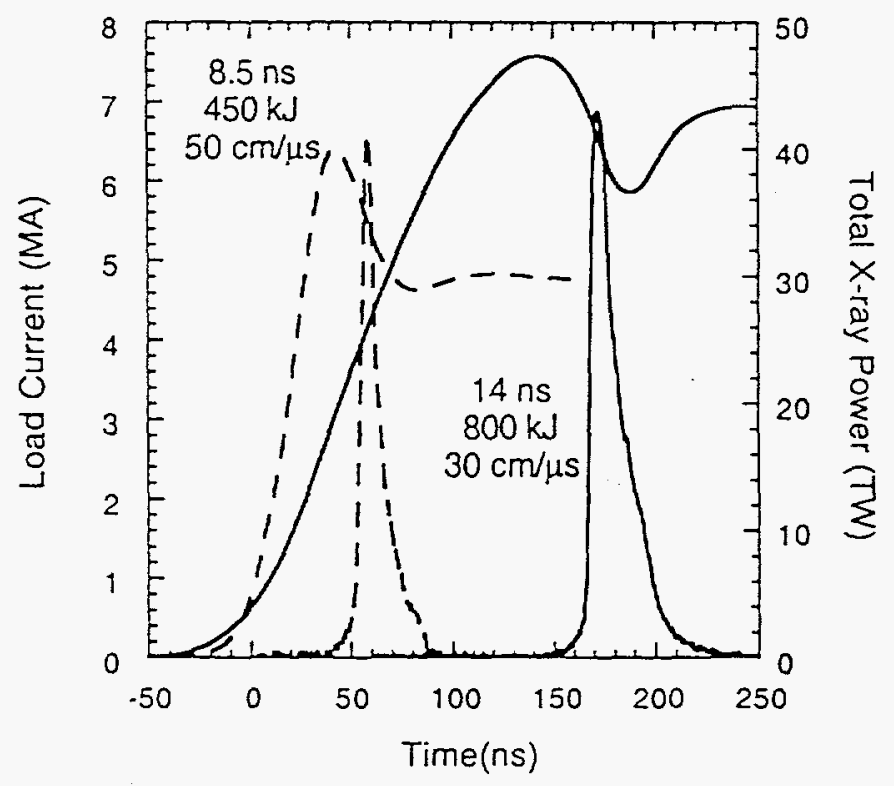

C. Deeney et al 


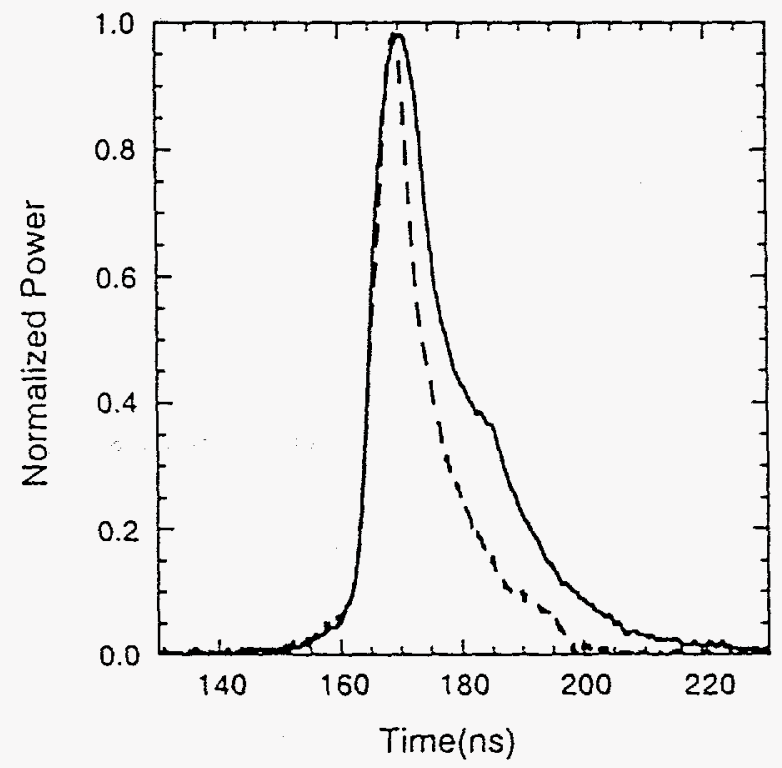

C. Deeney et al 


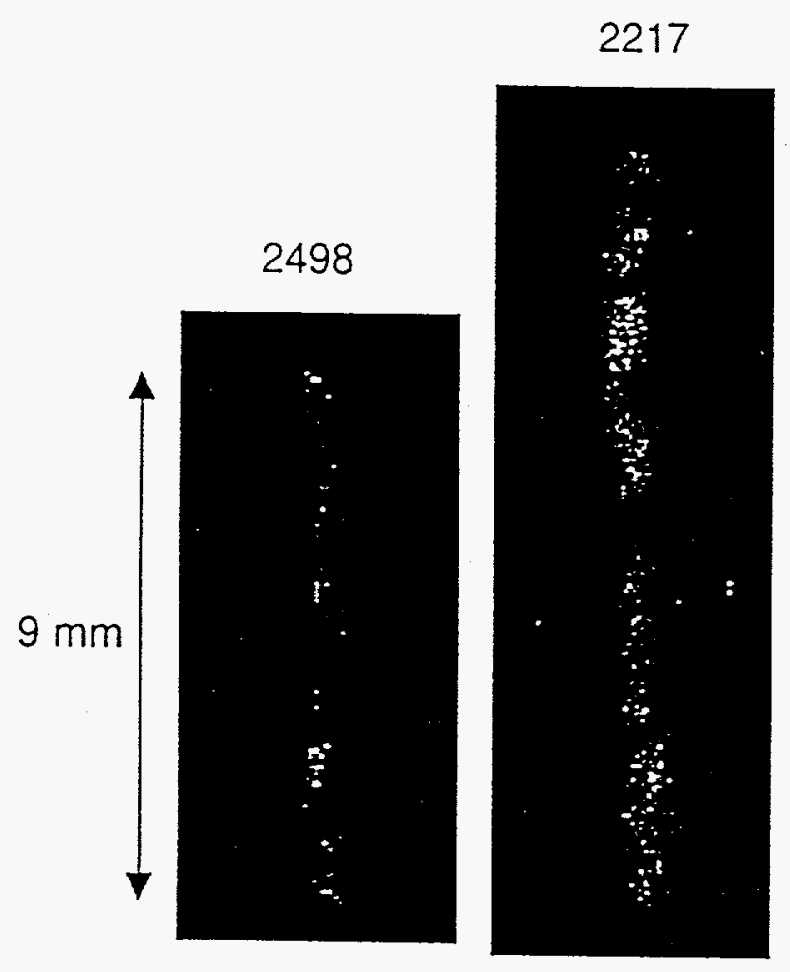

C. Deeney et al 

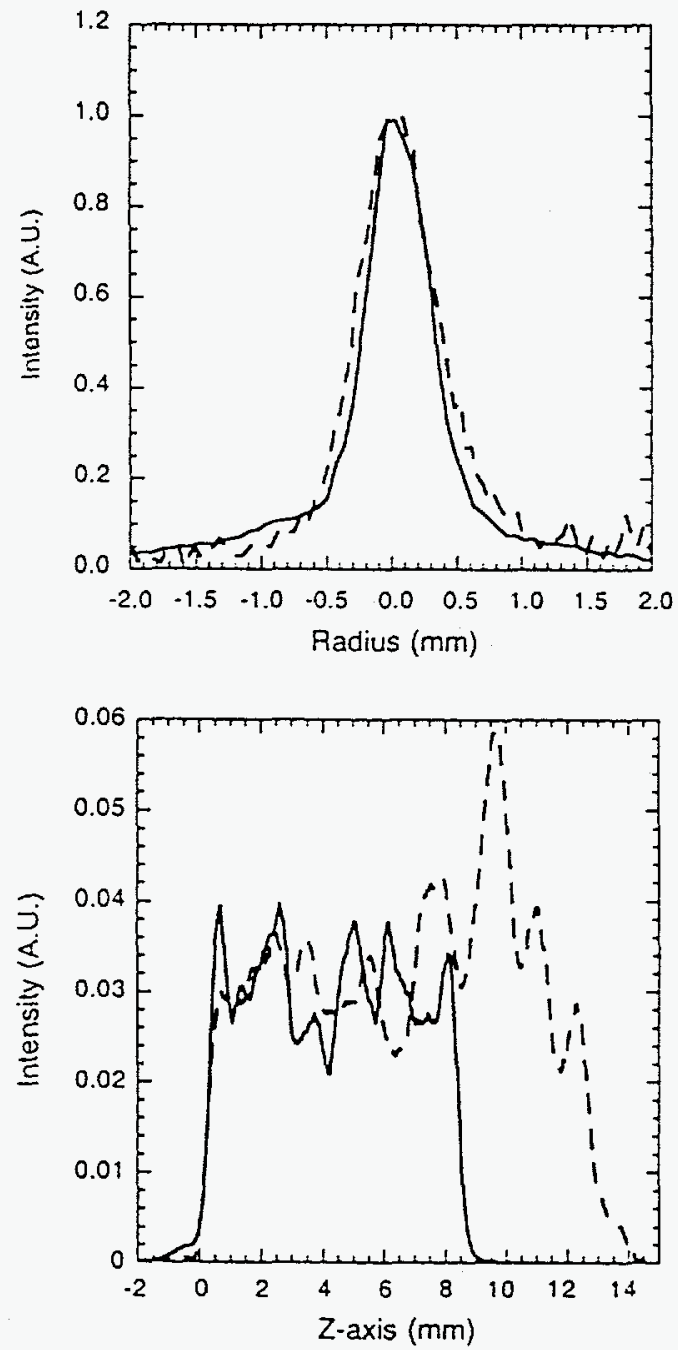

C. Deeney et al 


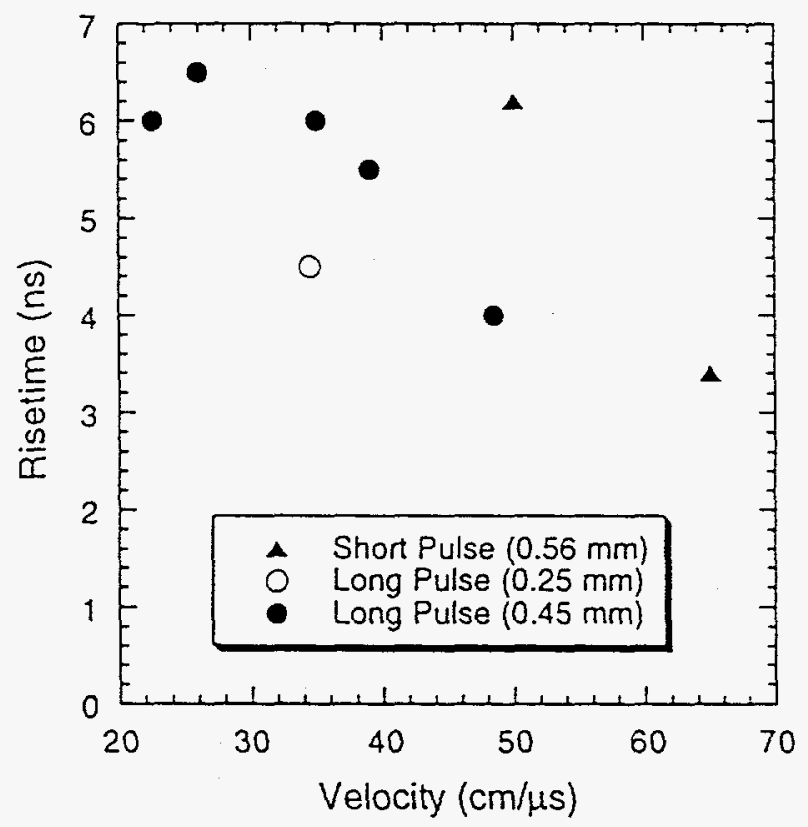

C. Deeney et al 
(a)
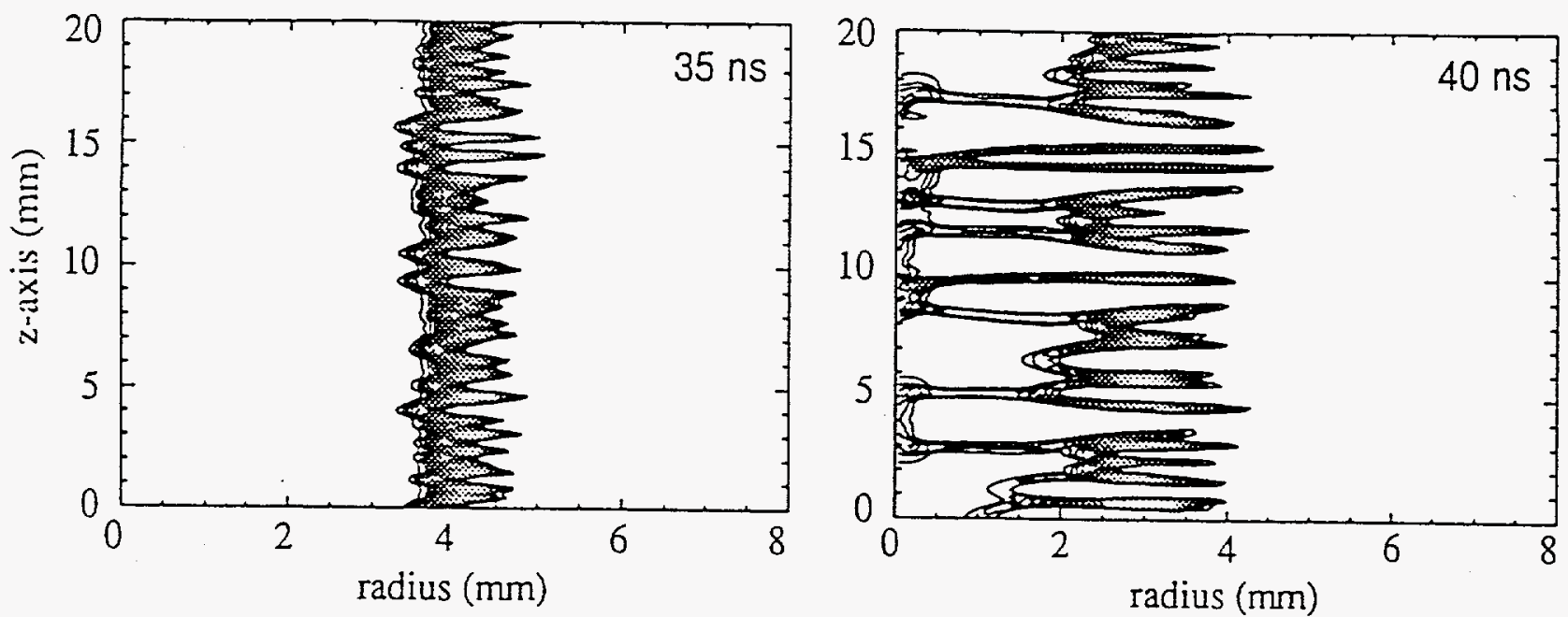

(b)
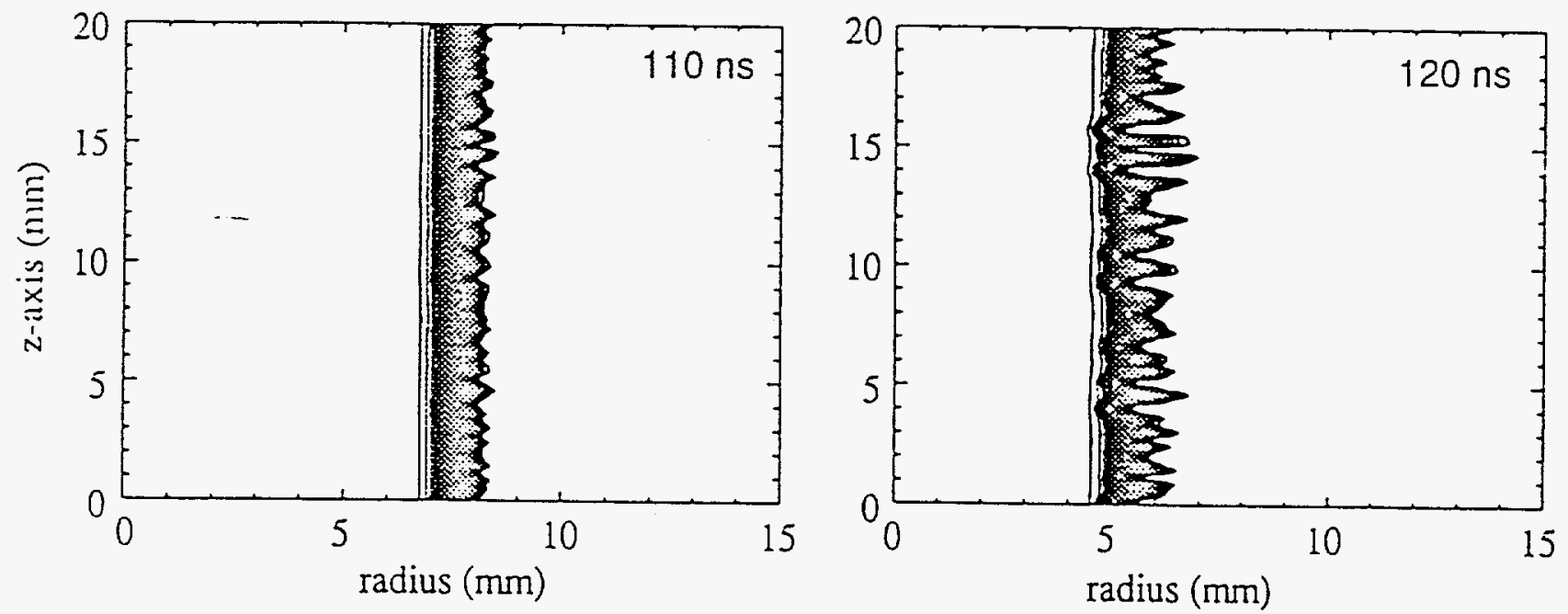

C. Deeney et al 


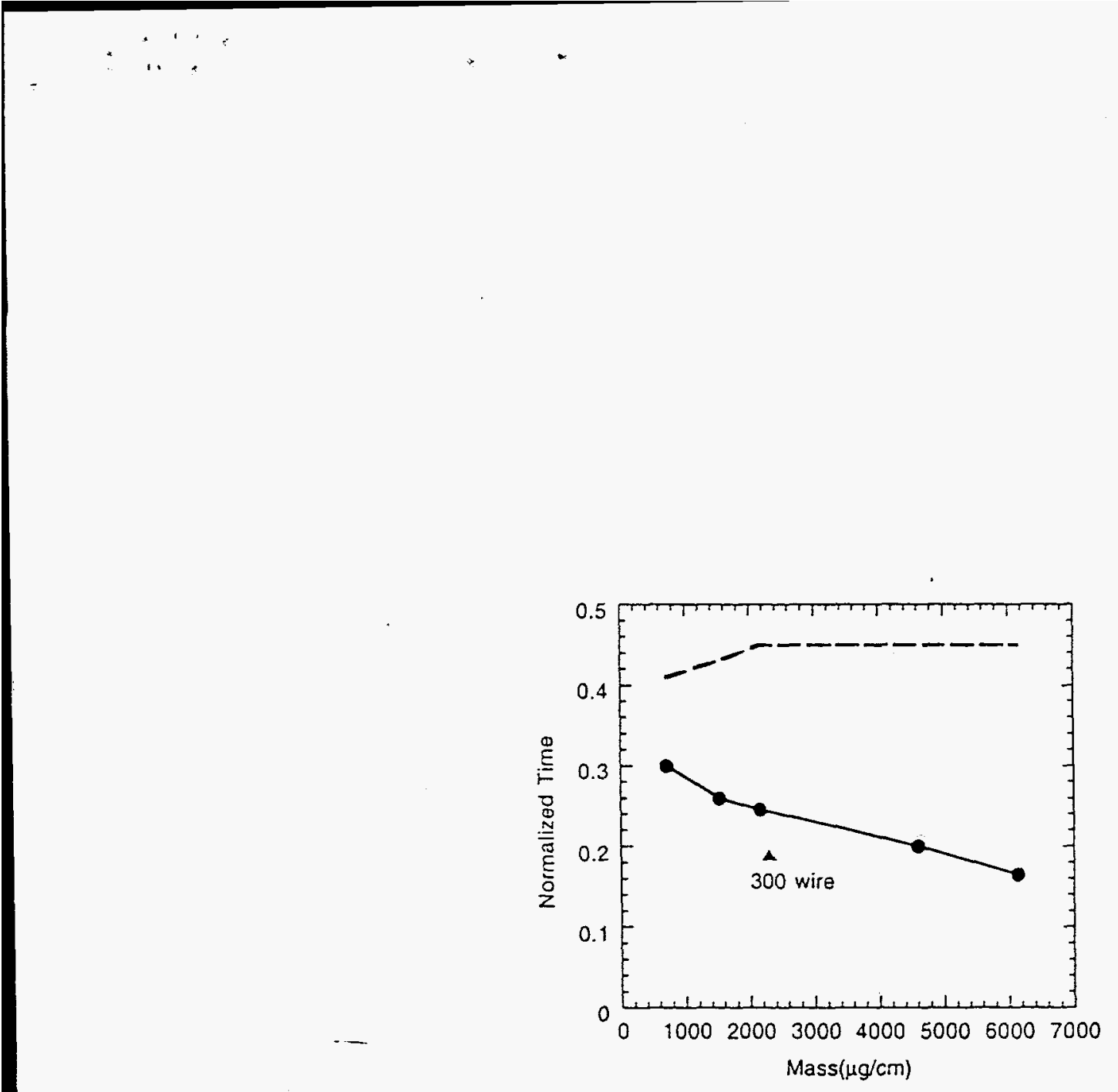

C. Deeney et al 
